\title{
Estágio supervisionado na instituição de ensino superior como direito humano aliado a formação da identidade docente
}

https://doi.org/10.11606/issn.1981-4690.v35inespp31-37

\author{
Lucas Sertorio Carrascoza* \\ Sergio Roberto Silveira*
}

*Escola de Educação

Física e Esporte,

Universidade São Paulo, São Paulo, SP, Brasil.

\section{Resumo}

A Declaração Universal dos Direitos Humanos (DUDH) representou a coligação entre as nações afim de assegurar direitos básicos humanos como o direito ao acesso, a igualdade, a liberdade, a proteção e a permanência. Nesse panorama, o direito a educação constitui-se como um dos direitos fundamentais mais relevantes para o futuro da humanidade, como símbolo da aquisição do conhecimento. Aliado a isso, a educação no ensino superior torna-se um elemento chave tanto para a formação inicial como continuada, na medida em que promove o alinhamento entre teoria e prática, por meio de disciplinas universitárias que envolvem o estágio supervisionado. Portanto, o objetivo desse ensaio é analisar a importância do estágio supervisionado no ensino superior como um direito humano aliado a formação da identidade docente. Por fim, há uma forte ligação entre os direitos humanos assegurados na DUDH e a formação da identidade docente, por meio de um processo de estágio supervisionado no ensino superior.

Palavras-chave: Educação; Docência; Formação profissional; Conhecimento.

\section{Introdução}

A Declaração Universal dos Direitos Humanos (DUDH), concebida inicialmente em 1948, representa um avanço, no que diz respeito a formação de uma aliança na direçáo de firmar um compromisso com os direitos humanos. A DUDH estabelecia um conjunto de artigos com o objetivo de assegurar direitos humanos relacionados com o direito ao acesso, a igualdade, a liberdade, a proteção e a permanência ${ }^{1}$.

Nesse sentido, o direito a educação básica gratuita entra em pauta como um dos direitos fundamentais da humanidade. No Brasil, os documentos oficiais como a LDB e a Constituição Federal de 1988 ressaltam a importância da educação como um direito que garante a assimilação, permanência e ressignificação do conhecimento da sociedade humana, o que forma o patrimônio cultural de nossa sociedade ${ }^{2}$.

Além disso, a educação no ensino superior é um potente instrumento de produçáo de conhecimento e formação profissional, na medida em que, sua garantia está aliada ao futuro da nação ${ }^{3}$. Tal relevância é dada, em sua maior parte, pelos estágios supervisionados, os quais promovem um ambiente ode teoria e prática se alinham, culminando na formaçáo de conhecimento sobre a prática ${ }^{4}$.

Isso posto, o objetivo desse ensaio é analisar a importância do estágio supervisionado no ensino superior como um direito humano aliado a formação da identidade docente.

\section{Discussão}

\section{Declaração universal de direitos humanos}

A Declaração Universal de Direitos Humanos (DUDH) é um documento histórico, que marca a história da civilização no que diz respeito à temática dos direitos humanos. As naçóes se comprometeram a assegurar o respeito aos direitos e as liberdades, por meio do ensino e da educação para todos. $\mathrm{O}$ artigo I 
representa sua ideia: "Todos os seres humanos nascem livres e iguais em dignidade e direitos. São dotados de razão e consciência e devem agir em relação uns aos outros com espirito de fraternidade" 5 .

O documento é composto de 29 artigos, sobre os quais é possível identificar que os direitos humanos perpassam desde o direito a vida, e a educação até os deveres com a comunidade que está inserido. Tais direitos possuem algumas características essenciais como a universalidade, a indivisibilidade e a interdependência, e por isso, devem ser tratados de forma justa, equitativa e igualitária por todos os governos ${ }^{1}$.

Nesse sentido, os artigos da DUDH compreendem direitos tais como: direito ao acesso, a igualdade, a liberdade, a proteção e a permanência. $O$ direito ao acesso compreende o direito à vida, de ser reconhecido como pessoa perante a lei, à propriedade, ao trabalho e a instruçáo de qualidade. A igualdade baseia-se na concepçáo de que não haverá distinçôes, de qualquer natureza, devido a condição política, a contrair patrimônio, a fundar uma família; sem qualquer restrição de raça, nacionalidade ou religiāo, a condiçôes justas e satisfatórias de trabalho e a uma justa remuneração. A liberdade compreende o direito de viver, pensar, agir e exprimir; da liberdade de expressão e de escrita, liberdade de opinião e a locomoção, assim como liberdade de pensamento e o direito contra a manutenção da pessoa escrava. Já o direito a proteção compreende o direito a proteção pessoal e a segurança pessoal. Por fim, a permanência expressa a necessidade de um suporte para manter sua vida em plenitude, assegurando para si e para sua família saúde e bem-estar, inclusive alimentação, habitação, cuidados médicos e serviços sociais ${ }^{1}$.

Assim sendo, a Declaração de Direitos Humanos constitui-se como um documento que garante e assegura os direitos básicos para a vida humana, os quais conferem dignidade, justiça e igualdade para todos. A educação é englobada na medida em que os direitos a instruçáo devem ser garantidos ao ser humano, independente de sua faixa etária, sexo, orientação sexual, cor ou qualquer outro aspecto.

\section{Direitos humanos e a Educaçáo Superior}

Como comentado anteriormente, a educação é um direito humano, pois é parte integrante da dignidade humana e contribui para ampliá-la com conhecimento, saber e discernimento ${ }^{3}$. Assim, a educação no ensino superior, por ser parte da educação no sentido amplo, é um processo complexo e que envolve múltiplas faces que se prolonga ao longo da vida profissional do indivíduo, uma vez que a aquisição e a relação com o conhecimento permitem a inserção, a apropriação, ressignificação e transmissão de uma parcela de conhecimento produzido pela sociedade ${ }^{1}$.

A associação das instituições de ensino superior (IES) com a promoção da educação encontra-se na Lei de Diretrizes e Bases da Educação Nacional - LDBEN, Lei 9394/96, em seu terceiro artigo, que afirma a importância do ensino superior de participar do processo de produção e difusão cultural, incentivando a pesquisa, a parceira na formaçáo continuada de profissionais e a divulgaçáo dos conhecimentos produzidos (culturais, científicos e tecnológicos) ${ }^{2}$.

Assim sendo, o artigo 26 da DUDH determina que o direito a educação deve se vincular a 3 objetivos específicos: (a) pleno desenvolvimento da personalidade humana e fortalecimentos do respeito aos direitos do ser humano e às liberdades individuais; (b) promoção da compreensão, da tolerância e da amizade entre as naçôes e a todos os grupos raciais e religiosos e (c) incentivo as atividades da Organização das Nações Unidas para a manutenção da paz.

\section{Direitos humanos e o estágio supervisionado}

A relação entre a educação, um direito garantido pela DUDH, durante o ensino superior e os estágios supervisionados pode ser observada em documentos oficiais, como na Lei de Diretrizes e Bases da Educação Nacional (LDB) em seu artigo 61. Tal passagem assegura que a formação de profissionais da educação tem como fundamento I a associação entre teorias e práticas, mediantes estágios supervisionados.

O estágio supervisionado é um espaço privilegiado para se trazer o professor-supervisor e seus saberes ao centro da formaçáo, considerando esse espaço como importante na formação inicial do professor. Além disso, o estágio supervisionado é uma iniciação à docência de estagiários, os quais buscam conhecer o espaço de trabalho, o dia a dia do profissional e os saberes necessários para a prática ${ }^{4}$.

Mais do que isso, para Burriolla (p.10) "o estágioé o lócus onde a identidade profissional é gerada, construida e referida; volta-se para o desenvolvimento de uma ação vivenciada, reflexiva e crítica e, por isso, deve ser planejado gradativamente e sistematicamente com essa finalidade".

Assim sendo, o estágio como reflexão da práxis possibilita aos alunos que ainda náo estáo formados aprender com aqueles que já possuem experiência na área, porém a discussão dessas experiências 
adquiridas, de suas possibilidades, e do fato de elas darem certo ou náo, configura um passo adiante a simples experiência. Assim, é necessário um professor supervisor, atrelado a faculdade/universidade como mediador dessas discussōes ${ }^{4}$. Por isso a importância do constante contato entre o docente da Universidade (orientador), o docente formador (supervisor) e o estudante-professor.

A supervisão das atividades que acontecem no estágio requer aproximação, partilha de informaçóes, saberes, capacidades, avaliação, aconselhamento, implementação de hipóteses de solução de problemas enfrentados pelos estagiários. Assim sendo, o contato aluno-professor e professor formador deve ser constante e o diálogo permanente ${ }^{7}$.

Isso poderia transformar o estágio em uma interação entre a universidade e a escola abrindo possibilidades de uma ação conjunta, na qual poderia haver benefícios para os dois lados, para o estudante, o qual adquire mais conhecimentos acerca da prática docente quanto para o professor-orientador. Além da valorizaçấo do professor supervisor no processo de formaçáo da identidade docente do estudante-professor.

Para os estagiários, descobre-se que ensinar não é fácil, pois significa levar a criança, jovem, adolescente ou adulto a conhecer novos mundos. O estágio é uma possibilidade de os estudantes vivenciarem uma parte do que é ser professor, aprendendo o cotidiano escolar e os aspectos da docência. Por sua vez, os professores formadores descobrem uma tarefa para além do ensinar alunos, tornando-se parte integrante do processo de formaçáo de novos professores ${ }^{8}$.

Assim, o estágio é um local fecundo dentro dos cursos de formação inicial, podendo de fato contribuir com a formação da identidade dos futuros profissionais, quando atrelado a uma proposta bem elaborada de formação. Quando a parceria escola-universidade de fato ocorre, essa capacidade pode ser potencializada.

Pimenta ${ }^{4}$ acenava para esse potencial do estágio como lócus teórico-prático o qual alunos que realizavam estágio supervisionado chegavam a conclusôes relevantes a respeito da prática, da escola e da educação, tais como percepção da relação entre teoria estudada, práticas escolares e açóes profissionais; conhecimento acerca de seus professores formados e o papel da docência em suas vidas; a clareza de que o estágio vai dar suporte a prática docente, principalmente para quem nunca esteve em sala de aula; convívio e interação em sala de aula; perceber que é possível colocar em prática muitos dos conhecimentos acumulados; vivenciar a partilha de trabalhos, o espírito de equipe entre os colegas nas atividades de estágio; compreensão dos elementos que interferem decisivamente na condução da sala de aula.

Podemos sintetizar que a educação, como direito humano básico que está garantido na DUDH, e o estágio supervisionado como um ambiente de direito do aluno, para que ele entre em contato com a prática docente se relacionam, na medida em que possibilitam a pleno aquisição, permanência e ressignificação do conhecimento.

\section{Direitos humanos e a formaçáo da identidade docente}

Numa perspectiva analítica, percebe-se a importância que a formaçáo da identidade docente possui em relação ao direito a educaçáo. $O$ primeiro objetivo presente no artigo $26 \mathrm{da}$ DUDH refere-se ao pleno desenvolvimento da personalidade humana e fortalecimentos do respeito aos direitos do ser humano e às liberdades individuais. A afirmação presente na Declaração possui direta relação com a formação docente, com o estágio supervisionado, e com os direitos do cidadão à instrução de qualidade no ensino superior.

Nesse sentido, a formação da identidade docente não é apenas um produto do estágio supervisionado, mas sim um direito humano, assegurado a todos por meio da Declaração dos Direitos Humanos.

Tal identidade docente é construída ao longo de sua trajetória pessoal e profissional, ou seja, de sua própria história e da relação entre os agentes e experiências vividas por esse indivíduo, o que perpassa pela segurança de exercer seus direitos conforme a DUDH. Entendese que a identidade docente é uma construção social de um sujeito historicamente localizado. Dessa forma, a identidade do profissional se baseia na significação social de sua profissão, no fluxo histórico de suas contradiçóes e em suas tradiçóes 4 .

Especificamente sobre a identidade docente, García, Hypólito e Vieira", compreendem como: "[...] uma construção social marcada por múltiplos fatores que interagem entre si, resultando numa série de representações que os docentes fazem de si mesmos e de suas funçôes, estabelecendo, consciente ou inconscientemente, negociaçōes das quais certamente fazem parte de suas histórias de vida, suas condiçôes concretas de trabalho, o imaginário recorrente acerca dessa profissão [...]" (p.54-55).

A identidade docente vai sendo construída com as experiências e a história pessoal de cada profissional, que por sua vez, está contido em uma sociedade que possui sua própria lógica interna. 
Para Ciampa ${ }^{10}$ (p.127), a identidade profissional se mescla com a seu papel docente na medida em que: "[...] cada indivíduo encarna as relaçóes sociais, configurando uma identidade pessoal. Uma história de vida. Um projeto de vida. No seu conjunto as identidades constituem a sociedade, ao mesmo tempo em que são constituidas por ela."

Assim, levando em consideraçáo a sociedade em que determinado indivíduo se encontra, emerge uma responsabilidade do professor para sua função social, promovendo-lhe comprometimento com aquilo que faz. O professor adquire essas competências por meio da formação escolar, formação inicial, experiências diversas, processos de formação continuada, influências sociais, entre outros ${ }^{11}$.
Parte das tarefas de "ser-professor" requer a compreensão de que a construção de quem se é ocorre num processo longo, pois é preciso tempo para se reconhecer como professor, encarnar seus valores e assimilar o conhecimento que lhe cabe. Mas, principalmente porque leva tempo até se reconhecer como um formador de geraçóes futuras. MocKeR ${ }^{12}$ aponta que a identidade docente envolve três dinâmicas: o ambiente externo da política, o contexto profissional e a experiência pessoal (Figura 1). Cada uma dessas dinâmicas apresenta condutas distintas do professor resultando num entendimento melhor acerca de sua compreensão de si próprio.

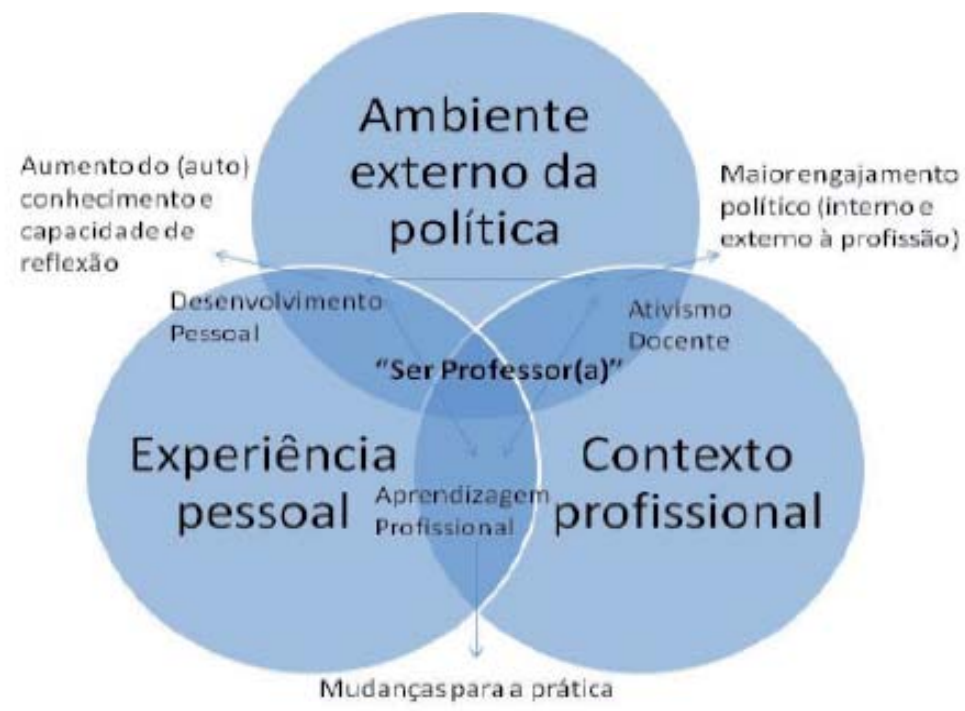

Figura 1: Formação e mediação da identidade docente (Adaptado de Mockler, 2011).

Assim sendo, os saberes que levavam professores a tomar determinada posição ou visão são sujeitos à influência do tempo e das experiências, assim como o professor está sob constante transformação no que tange crenças, habilidades, aptidóes relacionadas à própria profissão. Pode-se dizer que a identidade docente se constrói com base em um equilíbrio único entre as características pessoais e os percursos profissionais construídos ao longo da história de vida ${ }^{11}$.

Ser-professor é um processo que perpassa diversas questóes que vão desde sua socialização nos primeiros anos, enquanto aluno, seguindo por sua formação inicial, nos cursos de licenciatura, até tornar-se professor de fato, ficando em formação permanente . $^{\text {. }}$
Nessa lógica, leva-se em conta que a construção da identidade profissional é parte importante do processo de formação docente, já que ela se constitui desde os anos iniciais, se dando de forma mais intensa durante a formação inicial e nos momentos de aprendizado no interior da profissão. DAY ${ }^{13}$ afirma que o desenvolvimento profissional é um processo: "mediante o qual os professores, sós ou acompanhados, reveem, renovam e desenvolvem o seu compromisso como agentes da mudança, como os propósitos morais do ensino e adquirem e desenvolvem conhecimentos, competências e inteligência emocional, essenciais ao pensamento profissional...” (p.4). 
Como afirma $\operatorname{NóvoA}^{7}(\mathrm{p} .25)$, sobre a relação entre formação inicial e formação da identidade docente: "estar em formaçâo implica um investimento pessoal, um trabalho livre e criativo sobre os percursos e os projectos próprios, com vista à construção de uma identidade, que é também uma identidade profissional." A formação profissional se constrói através de um trabalho de reflexividade crítica sobre as práticas e de (re)construçáo permanente de uma identidade pessoal.

DoMinicÉ É $^{14}$ complementa esse pensamento:

"Devolver à experiência o lugar que merece na aprendizagem dos conhecimentos necessários à existência (pessoal, social e profissional) passa pela constatação de que o sujeito constrói o seu saber activamente ao longo do seu percurso de vida. Ninguém se contenta em receber o saber, como se ele fosse trazido do exterior pelos que detêm os seus segredos formais. A noção de experiência mobiliza uma pedagogia interactiva e dialógica." (p.149-150).

É importante reconhecer que as características do desenvolvimento pessoal e profissional, ressaltam o sentido de uma epistemologia da prática, isso se opóe a tendências que reduziam a profissáo docente a um conjunto de técnicas, e que contribuíam para a crise de identidade dos professores ${ }^{7}$. Como argumenta TARDIF ${ }^{15}$ (p.218), os saberes são provenientes de quatro fontes:

- Saberes da formação profissional (das ciências da educação e da ideologia pedagógica mobilizada em conformidade come essa atividade, transmitidos pelas instituições formadoras).

- Saberes de disciplinas (que correspondem aos saberes sociais sistematizados e tematizados na instituição universitária).

- Saberes curriculares (saberes sociais que a escola/sociedade selecionou para serem transmitidos às futuras gerações).

- Saberes da experiência (desenvolvidos pelo professor no exercício de sua profissão).

Assim, há uma inversão de princípios quando passa a se reconhecer primordial o saber da prática e o saber da experiência, como meios para compreender quem sáo os professores, porque tomam determinadas decisóes, quais são suas crenças, o que influencia no seu trabalho e outros tantos questionamentos atrelados à docência ${ }^{16}$.
Altet ${ }^{17}$, ao refletir sobre a importância da dimensão prática na carreira do professor, explica que:

"[...] o saber da prática é construído na ação, com finalidade de ser eficaz; ele é contextualizado, encarnado e finalizado, transformando-se em um saber adaptado à situação. Essa adaptação do saber é construída a partir da experiência vivida com a ajuda de percepçôes e interpretaçôes dadas as situaçôes anteriormente vividas." (p.31).

Dessa forma, os saberes da experiência constituem o elemento fundamental na formaçáo inicial do professor e não podem ser ignorados na definição dos currículos. Isso porque, o saber da experiência é o saber próprio do professor, constituinte de sua própria identidade ${ }^{18}$. É o saber que se desenvolve em sua práxis social cotidiana como ator social, educador e docente. É o saber construído em interação com os outros sujeitos e em relação com a pluralidade dos demais saberes disponíveis. Assim é fundamental mais estudos sobre os saberes de experiência, pois THERRIEN ${ }^{18}$ :

"Considerando o processo de formação de professores como elo inseparável da prática docente, numa perspectiva dinâmica de formação permanente, torna-se crucial identificar, descrever e analisar os elementos desse saber inter-relacionados com os saberes pedagógicos e disciplinares oriundos de instituiçóes de formação dos profissionais de ensino, bem como os saberes curriculares definidos pela instituição escolar onde devem ser transmitidos." (p.10).

Por meio desse complexo processo, o professor vai construindo os saberes docentes necessários para sua práxis, à prática docente. O lócus principal no qual teoria e prática se fundem é o ambiente de trabalho para os profissionais já formados, e no que tange a formação inicial, o estágio supervisionado é essencial pois possibilita que sejam trabalhados aspectos indispensáveis a construção da identidade docente, dos saberes e das posturas específicas do profissional docente ${ }^{4}$. Isso demonstra a importância dos direitos humanos na vida pessoal e profissional de um indivíduo, na medida em que os direitos a acesso, igualdade, liberdade, proteção e permanência sejam, de fato, assegurados.

\section{Considerações finais}

O presente ensaio tinha como objetivo tecer uma relação entre os direitos humanos presentes na DUDH

e o estágio supervisionado no ensino superior como elemento formador da identidade docente. Pode-se 
perceber que os a Declaração Universal de Direitos Humanos foi um marco histórico, na medida em que garantiu a todos os cidadáos e cidadâs o direito ao acesso, a igualdade, a liberdade, a segurança e a permanência.

Seria muito difícil de conceber um sistema educacional de qualidade sem que esses direitos fossem assegurados. $\mathrm{O}$ direito a educação básica e gratuita, conforme os documentos oficiais brasileiros, asseguraram o direito ao estágio supervisionado, o que consequentemente, levou a formação das inúmeras identidades docentes no país.

Assim sendo, há uma forte ligação entre os direitos humanos assegurados na DUDH e a formação da identidade docente, ao longo de um processo de estágio supervisionado no ensino superior.

\begin{abstract}
Supervised internship in the higher education institution as a human right related to the formation of the professional identity

The Universal Declaration of Human Rights (UDHR) represented the coalition between nations to ensure basic human rights such as the right to access, equality, freedom, protection and permanence. In this context, the right to education is one of the most relevant fundamental rights for the future of humanity, as a symbol of the acquisition of knowledge. Allied to this, higher education becomes a key element for both initial and continuing education, as it promotes the alignment between theory and practice, through disciplines that involves the supervised internship. Therefore, the objective of this essay is to analyze the importance of supervised internship in higher education as a human right related to the formation of the teaching identity. Finally, there is a strong link between human rights enshrined in the UDHR and the formation of the teaching identity, through a supervised internship process in higher education.
\end{abstract}

KEYWORDS: Education; Teaching; Professional formation; Knowledge.

\title{
Referências
}

1. Silveira SR, Freudenheim AM, Bassi P, Oliveira JA. Núcleo de Direitos Humanos da Escola de Educaçáo Física e Esporte da USP: uma perspectiva educativa. Rev Bras Educ Fís Esporte. 2020;34(nesp):1-9.

2. Brasil. Constituição da República Federativa do Brasil. Brasília, Senado Federal, 1988.

3. Claude RP. Direito à educação e educação para os direitos humanos. Sur Rev Int Direitos Human. 2005;2(2):36-63.

4. Pimenta SG. Formação de professores: Identidade e saberes da docência. In: Pimenta SG, organizador. Saberes pedagógicos e atividade docente. São Paulo: Cortez, 1999. Edição 2019.

5. Declaração Universal dos Direitos Humanos. Assembleia Geral das Naçôes Unidas em Paris. 10 dez. 1948.

6. Buriolla MA. O estágio supervisionado. São Paulo: Cortez, 1999.

7. Nóvoa A. Para o estudo sócio-histórico da gênese e desenvolvimento da profissáo docente. Teoria Educ. 1991;4:109-139.

8. Benites LC. O professor-colaborador no estágio curricular supervisionado em Educação Física: perfil, papel e potencialidades. 180f. Tese (Doutorado em Ciência da Motricidade). Instituto de Biociências, Universidade Estadual Paulista, Rio Claro, 2012.

9. Garcia MA, Hypolito A, Vieira J. As identidades docentes como fabricação da docência. Educ Pesq. 2005;31(1):45-56.

10. Ciampa AC. A história do Severino e a história da Severina: um ensaio de psicologia social. Sáo Paulo: Brasiliense, 1998.

11. Iza DFV, Benites LC, Sanches NL, Curino M. Identidade docente: as várias faces da constituição do ser professor. Rev Eletrônica Educ. 2014;8(2):273-292.

12. Mockler N. Beyond 'what works': understanding teacher identity as a practical and political tool. Teach Theor Pract. 2011;17(5):517-528. 
13. Day C. O desenvolvimento profissional dos professores em tempos de mudanças e os desafios para as universidades. Rev Estudos Curriculares. 2003;1:151-188.

14. Dominicé P. L'histoire de vie comme processus de formation. Paris: Éditions L'Harmattan, 1990.

15. Tardif M. Saberes docentes e formação profissional. Petrópolis-RJ: Vozes, 2002.

16. Sarmento MJ. A vez e a voz dos professores: contributo para o estudo da cultura organizacional da escola primária. Porto, Portugal: Porto, 1994.

17. Altet M. As competências do professor profissional: entre conhecimentos, esquemas de ação e adaptaçáo, saber analisar. In: Paquay L, et al., organizadores. Formando professores profissionais: Quais estratégias? Quais competências? Porto Alegre: Artmed, 2001. p. 23-35.

18. Therrien J. O saber social da prática docente. Fortaleza: Faculdade de Educação.Universidade Federal do Ceará, 1993.

\begin{tabular}{r|r} 
ENDEREÇo & \\
Lucas Sertorio Carrascoza & \\
Universidade de São Paulo & \\
Escola de Educação Física e Esporte & Recebido: 04/01/2021 \\
Campus Cidade Universitária & Aceito: 06/01/2021 \\
Av. Prof. Mello Moraes, 65 & \\
05508-030 São Paulo - SP - Brasil & \\
E-mail: lucas.carrascoza@usp.br &
\end{tabular}

